Sharif University of Technology
Scientia Iranica
Transactions A: Civil Engineering
hCIENTIA
IRAN I CA

\title{
Investigation of flow patterns around rectangular and oblong piers with collar located in a 180-degree sharp bend
}

\author{
A. Keshavarz ${ }^{a}$, M. Vaghefi ${ }^{a, *}$, and G. Ahmadi ${ }^{b}$ \\ a. Department of Civil Engineering, Persian Gulf University, Shahid Mahini St., Bushehr 7516913798, Iran. \\ b. Department of Mechanical and Aeronautical Engineering, Clarkson University, 8 Clarkson Ave, Potsdam, NY 13699, New York, \\ $U S A$.
}

Received 27 January 2020; received in revised form 2 January 2021; accepted 22 February 2021

\author{
KEYWORDS \\ Flow patterns; \\ 180-degree sharp \\ bend; \\ Oblong pier; \\ Rectangular pier; \\ Turbulence kinetic \\ energy.
}

\begin{abstract}
Flow in river bends is associated with generation of secondary flows, which leads to the development of a rather complicated flow pattern around bridge piers located in the bend. The present study investigated the flow patterns around models for rectangular and oblong piers with a collar located at the 90-degree angle of a 180-degree sharp bend in an experimental plume. The 3D flow velocity data were collected using a Vectrino velocimeter. The experimental results indicated that the presence of the rectangular pier caused a more intense deviation of the streamlines towards the outer bank of the bend. Furthermore, installation of the oblong pier, rather than the rectangular pier, decreased the maximum secondary flow power and angular velocity by $35 \%$ and $45 \%$, respectively. It was also found that the maximum turbulence kinetic energy around the two piers was not significantly different; however, by installing the rectangular pier, a region with high values of turbulence kinetic energy was formed at $90^{\circ}$ near the inner bank. Moreover, installation of the oblong pier could reduce shear stress.
\end{abstract}

(C) 2021 Sharif University of Technology. All rights reserved.

\section{Introduction}

Flow patterns in rivers, especially at bends or in the vicinity of hydraulic structures, are of particular interest due to their importance in scouring. A combination of the main curved stream and lateral secondary flows at the bend generates rather complex helical flows that result in scours at the outer wall and sedimentation in the vicinity of the inner bank. Furthermore, the interaction of the flow with hydraulic structures leads

\footnotetext{
*. Corresponding author. Tel.: +9877 31222401;

Fax: +987733440376

E-mail addresses: Arsalan.keshavarz2011@gmail.com (A.

Keshavarz); Vaghefi@pgu.ac.ir (M. Vaghefi);

gahmadi@clarkson.edu (G. Ahmadi)
}

to the generation of down flow streams and scour holes. Therefore, studies on flow patterns in rivers and river bends have gained considerable significance. Hence, numerous studies on the flow patterns in a straight channel, river bends, and around hydraulic structures have been reported in the literature.

Albayrak and Lemmin (2011) experimentally investigated the influence of the ratio of channel width to flow depth on secondary flows in a straight channel [1]. Ataie-Ashtiani and Aslani-Kordkandi (2012) examined the flow pattern around twin round bridge piers in a straight channel. Their results indicated that the down flow streams and Turbulence Kinetic Energy (TKE) were higher between the two piers than those on their outer edges. The bed shear stress between the two piers was also nearly twice that at the outer edges of the piers [2]. Akib et al. (2014) 
experimentally investigated the scour and flow pattern mechanism around different complex bridge pier groups in a straight-path channel [3]. Tao and Yu (2014) employed the Computational Fluid Dynamics (CFD) software to study the flow pattern and shear stress around bridge piers with different shapes and different aspect ratios at different angles of attack in a straight channel. According to their obtained results, powerful down flow streams were generated in front of the piers with blunt noses. Furthermore, the incoming flow angle of attack had a significant effect on the flow pattern around the piers. In addition, as the aspect ratio increased, the sensitivity to angle of attack grew stronger [4]. Jaman et al. (2017) conducted an experimental investigation of the flow properties around triple bridge piers in a channel with a straight path [5]. Keshavarzi et al. (2018) examined the flow pattern around two in-line bridge piers with different distances from each other in a laboratory channel with a straight path [6]. Jalil (2018) studied the flow pattern around 22 different shapes of bridge piers in a straight channel numerically and experimentally [7]. Chavan et al. (2018) experimentally studied the flow pattern around circular and oblong piers in a straight channel. They found that the wake vortices around the oblong pier were weaker than those around the circular pier [8]. Das and Mazumdar (2018) examined the flow pattern around twin square bridge piers in inline-front pier and eccentric-rear pier arrangements in a straight channel. Their results indicated that the horseshoe vortices were more powerful in the eccentricrear pier arrangement than those in the inline-front pier arrangement [9]. Chen et al. (2018) conducted an experimental and numerical investigation of the flow pattern and scour around a circular bridge pier with a hooked collar in a straight channel. They found that in contrast to the absence of hooked collars, using the hooked collar would decrease the power of down flow streams, horseshoe vortices, and kinetic energy [10]. Chavan et al. (2019) studied the flow pattern and scour around a circular pier with both no seepage and with downward seepage conditions in a straight path [11]. Lee and Hong (2019) conducted an experimental study on the flow pattern around a bridge pier before and after scour in a straight path. Measurements indicated that the flow velocity values upstream of the pier, where horseshoe vortices came from, were considerably different before and after scour [12]. Carnacina et al. (2019) studied the flow behavior in a laboratory channel with a straight path under the free-surface and pressure-flow conditions [13]. Vijayasree et al. (2019) studied the flow pattern and scour around five different pier shapes in a straight channel and found that the maximum scour depth was created on the upstream side of the rectangular pier [14]. Choufu et al. (2019) used the Flow-3D software to carry out a numerical study on the effect of the orientation and spatial setup of Groynes on flow pattern, bed erosion, and sedimentation in a straight channel [15]. Gautam et al. (2019) examined the flow pattern around single and group bridge piers in a straight path with three different Reynolds numbers. They reported that the flow patterns around the group and single piers were significantly different. A reversed flow was observed on the downstream side of the single pier with lower Reynolds numbers. Upon increasing the Reynolds number, this reversed flow was transported towards the upstream side [16]. Namaee and Sui (2020) investigated the flow field under an open channel, smooth ice-covered and rough ice-covered flow conditions in a straight path around four pairs of bridge piers [17]. Vijayasree et al. (2020) compared the flow patterns around oblong and circular piers in a laboratory channel with a straight path [18]. Lade et al. (2020) examined the effect of mining pit on hydrodynamics around circular bridge piers in a laboratory channel with a straight path [19].

Few researchers have investigated flow pattern in curved channels. Abhari et al. (2010) conducted an experimental and numerical study of the flow pattern in a channel with a 90-degree bend and found that the maximum flow velocity was observed near the inner wall at about $30^{\circ}$ angles of the bend and then, the flow leaned towards the outer wall thereafter. They also compared the experimental data and earlier numerical results and found that the SSIIM 1.1 software program was capable of modeling the flow in a 90-degree bend [20]. Stoesser et al. (2010) simulated the flow pattern in a meandering path using a CFD model [21]. Uddin and Rahman (2012) studied the flow pattern in the bend of Jamuna River. They found that the flow velocity near the walls at each section was approximately 1.1-1.3 times the flow mean velocity [22]. Gholami et al. (2014) investigated the flow pattern in a 90-degree bend both experimentally and numerically. Their obtained results indicated that the maximum flow velocity consistently occurred near the inner bank [23]. Vaghefi et al. (2016) conducted an experimental study on wall shear stress and secondary flows in a 180-degree sharp bend. Their results indicated that the maximum shear stress occurred at a distance of $40^{\circ}-60^{\circ}$ angles of the bend near the inner wall [24].

Some researchers have investigated the effect of hydraulic structures on the flow pattern in curved channels. Vaghefi et al. (2015) utilized the Flow-3D software to study the flow pattern around a T-shaped spur dike located at a 90-degree bend, accompanied by a support structure on the upstream side. They found that upon increasing the distance of the support structure from the spur dike, the secondary flows around the spur dike would be reduced [25]. Mehraein et al. (2017) investigated the flow pattern and scour around a Tshaped spur dike in a bent channel with a 90-degree 
bend [26]. Abdi Chooplou et al. (2018) carried out an experimental study on the flow pattern around a circular bridge pier accompanied by submerged vanes in a 180-degree sharp bend [27]. Asadollahi et al. (2019) compared the numerical and experimental results of the flow pattern and scour in cases with no pier, one pier, and triple piers placed in a bent channel with a 180degree bend [28]. Moghanloo et al. (2019) experimentally investigated the effect of collar thickness on the flow pattern around an oblong pier located in a 180degree sharp bend. Their obtained results indicated that the turbulent kinetic energy was reduced by $60 \%$ with the increase of the collar thickness [29]. Asadollahi et al. (2020) employed the SSIIM software to conduct a numerical study of the flow pattern and scour around a group of bridge piers implemented at different angles of a 180-degree bend [30]. Sedighi et al. (2020) carried out an experimental study of scouring around inclined paired piers under clear water, incipient motion, and movable bed conditions at different angles of a 180degree bend [31].

Based on the mentioned literature, it can be concluded that studies of the flow pattern in bends have gained significance owing to the presence of helical flows. The shape of bridge piers is also one of the parameters that contributes to flow pattern changes. However, hydraulic engineers have always sought methods for controlling scour around bridge piers, among which use of collars is a well-known one. With a collision of the flow with the pier, downflow streams are developed in the vicinity of the upstream pier nose, which is one of the main factors involved in creation of a scour hole. Using a collar reduces the power of the downflow streams as they collide with the collar, thus leading to a reduction in depth and volume of the scour hole in sensitive areas around the pier. However, the mechanism controlling the flow pattern around piers with collars, especially in bends, has received little attention. Previous studies mostly investigated the flow pattern in straight paths without supportive structures. Therefore, the present study employed both a supportive structure (collar) and a bent channel to experimentally examine the flow pattern in a 180 degree sharp bend around rectangular and oblong piers with a collar. Parameters such as angular velocity, secondary flow intensity, wall shear stress, and TKE were calculated and compared. The obtained results indicated that using an oblong pier, instead of a rectangular pier, would decrease the angular velocity and secondary flow power. In addition, since the oblong pier is aerodynamic in comparison with the rectangular pier, the shear stress values near the bed are smaller around the oblong pier, thus resulting in smaller depth and volume of the scour hole created around the oblong pier than those created around the rectangular pier. However, the maximum value of turbulent kinetic energy around the two piers was not significantly different.

\section{Materials and methods}

The experimental studies were conducted in a plume with a curved channel and a 180-degree bend. This plume is shown in Figure 1. Vaghefi and Akbari (2019) examined the construction stages of this channel step by step [32]. The channel is $1 \mathrm{~m}$ wide and $70 \mathrm{~cm}$ high with a rectangular cross-section. The straight upstream and downstream channels are 6.5 and $5.1 \mathrm{~m}$ long, respectively. The central curvature radius of the channel bend is $2 \mathrm{~m}$. With a ratio of $R / B=2$, this channel is qualified as a sharp bend channel, where $R$ and $B$ are the central curvature radius and channel width, respectively. This laboratory hosts sediment particles with the average diameter of $1.5 \mathrm{~mm}$ and a standard deviation of $1.14 \mathrm{~mm}$. All experiments were conducted under incipient motion conditions at the upstream path of the bend with $U / U c=0.98$. All tests were conducted with a discharge of 70 liters per second and a depth of $18 \mathrm{~cm}(y=18 \mathrm{~cm})$. The Froude and Reynolds numbers were 0.3 and approximately 50000 , respectively.

The rectangular and oblong piers with collars located at the 90-degree angle of the bend were used in these experiments (oblong pier is a replica of the rectangular pier with rounded corners). The crosssections of these piers are shown in Figure 2. According to Chiew and Melville (1987), to eliminate the effect of the walls, the pier width must not exceed $10 \%$ of the channel width [33]; therefore, piers with a width of $5 \mathrm{~cm}$ and length of $20 \mathrm{~cm}(L / D=4)$ were employed in this study. Here, $L$ is the pier length and $D$ the pier width. Furthermore, collars with the width four times the pier width $(D c / D=4)$ and a thickness of $0.12 \mathrm{D}$ at the elevation of $0.4 \mathrm{D}$ lower than the bed level were utilized. Here, the collar width is $D c=20 \mathrm{~cm}$.

Before conducting the flow pattern experiments,

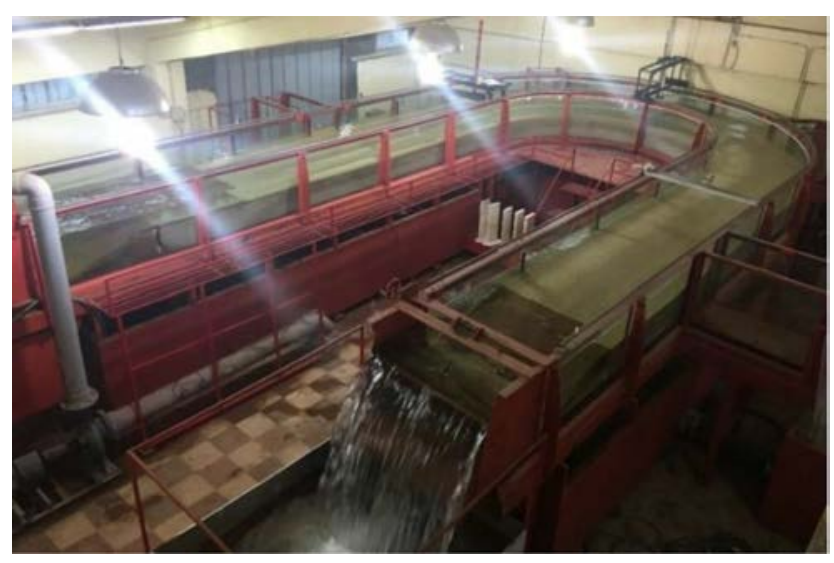

Figure 1. The laboratory channel used. 


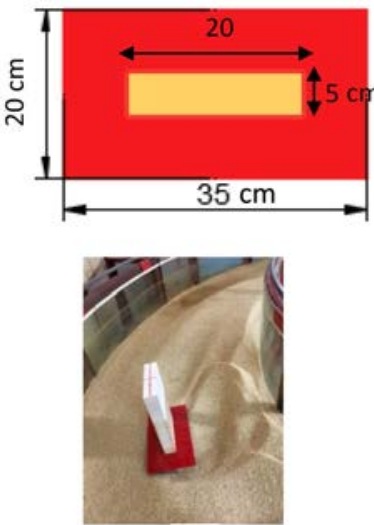

(a)
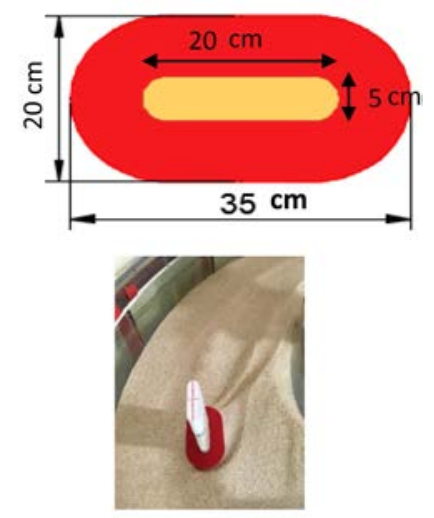

(b)
Figure 2. Cross-sections of the piers with collars: (a) Rectangular pier and (b) oblong pier.

the scour test around the piers was first done with 15 hours of relative equilibrium time. Figure 3 illustrates the bed topography after running the scour test. As observed, the main scour hole is formed in the vicinity of the piers between the angles of $85^{\circ}$ and $110^{\circ}$, and the sediments are collected and accumulated downstream of the 120-degree angle. It is also observed that the depth of the hole, height of the accumulated sediments, and sediment reaching towards the end of the bend are higher with installation of the rectangular pier than those with installation of the oblong pier.

After the completion of the scour test, the plume is completely drained and fiberglass paste is added to fix the bed; then, the flow pattern experiment is conducted. In this respect, the Vectrino $3 \mathrm{D}$ velocimeter was utilized to collect the velocity data at different points in the curved channel. The velocimeter was set at $25 \mathrm{~Hz}$ frequency. At each point of the experimental mesh, the velocimeter collected about 1500 instantaneous velocity data points in a duration of one minute and gave the mean of the data as the velocity at that point.

Figure 4(a) shows the locations (angle and radial locations) of the points at which the experimental data were collected. Of note, the data collection was conducted at 39 transverse sections along the bend

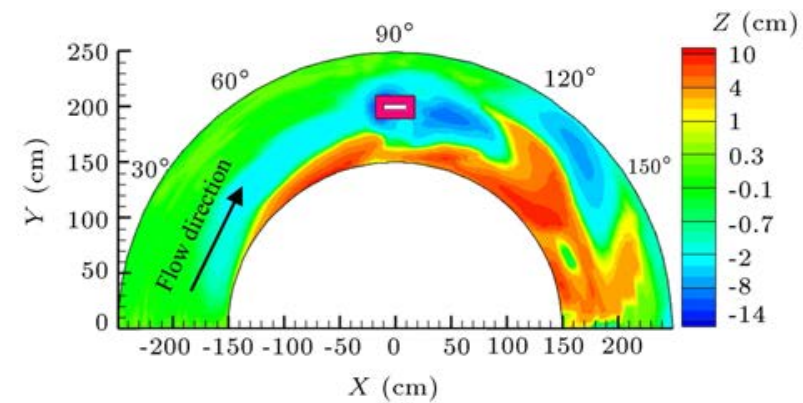

(a) at nine depths and 33 velocity data were collected at each transverse section. Figure 4(b) and (c) show the pictures of the down-looking and side-looking configurations of the Vectrino $3 \mathrm{D}$ velocimeter in the plume.

\section{Results and discussion}

Figure 5 illustrates the sample streamlines on planes at levels of $95 \%, 50 \%$, and $5 \%$ of the flow depth from the initial bed level for both rectangular and oblong piers. These streamlines are plotted for the mean flow velocities on each plane. According to Figure $5(\mathrm{a})$ and (b), the streamlines at the level near the water surface in the first half of the bend are mostly directed towards the outer wall due to the presence of secondary flows in the bend. However, according to Figure 5(e) and (f), the streamlines near the bed level are mostly directed towards the inner wall that results in sediment transport towards the inner bank, generation of sedimentary piles in this area, and erosion of the mid-channel.

Reverse flows are observed in Figure 5(a) and (b) near the water surface in the vicinity of the piers. These reverse flows in the opposite direction of the mean flow stream are created due to the interaction of the flow with the pier. Given the fact that the streamlines near the water surface lean towards the outer wall of the bend, these reversed flows mostly occur at the outer half of the channel width in the vicinity of the pier. Figure 5(a) shows that the reverse flows around the rectangular pier are stronger than those near the oblong pier, and they extend from $70^{\circ}$ to $130^{\circ}$ angles in the bend and cover almost the entire channel width. On the contrary, according to Figure 5(b), there are weaker reverse flows around the oblong pier, and the disorders in the streamlines are observed only around the upstream nose of the pier. The geometries of the piers are the main reason for such differences. The rectangular pier has higher resistance against the flow due to its wide nose and sharp edge; therefore, the flow is markedly diverted backwards or pushed to the sides after encountering this pier. While the oblong pier with its rounded edges is more aerodynamic than the

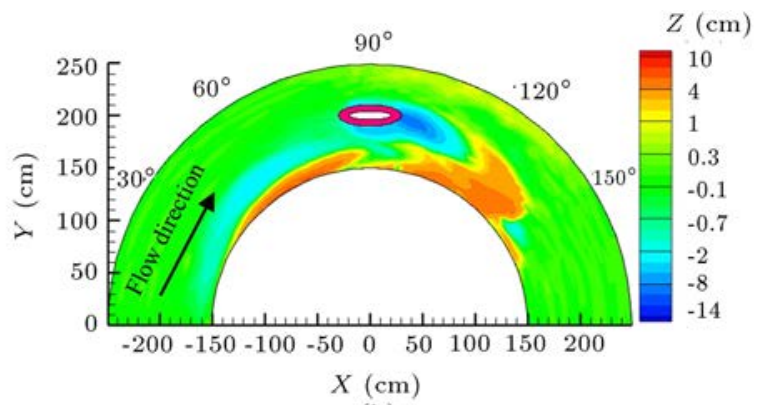

(b)

Figure 3. Bed topography with installation of: (a) Rectangular and (b) oblong piers at the $90^{\circ}$ angle of the bend. 


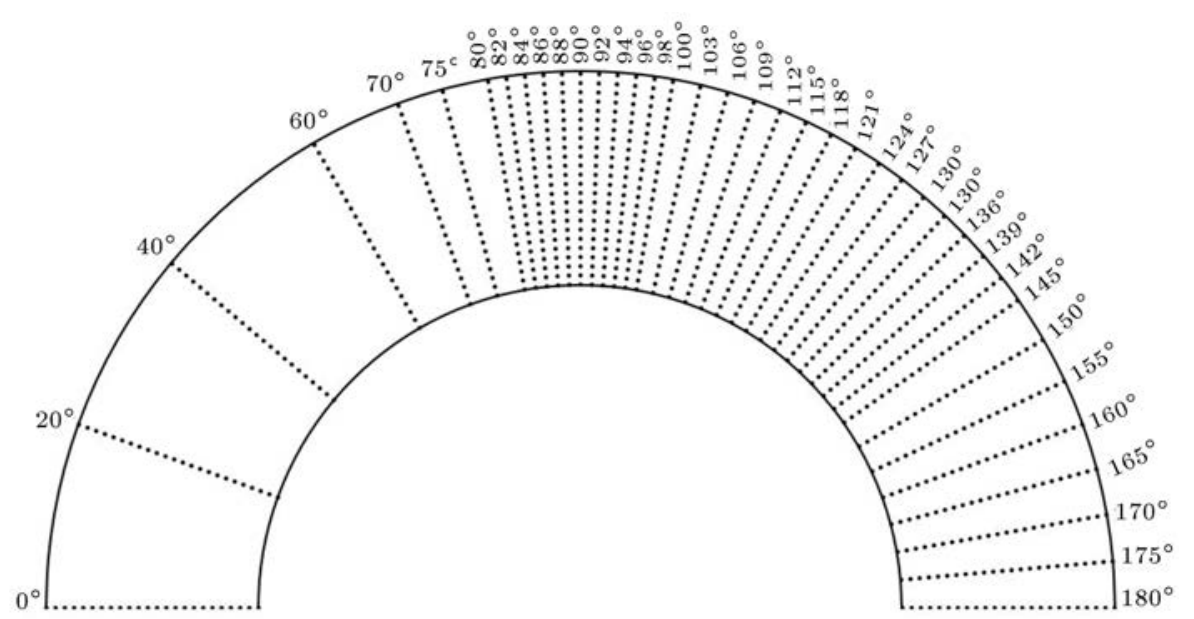

(a)

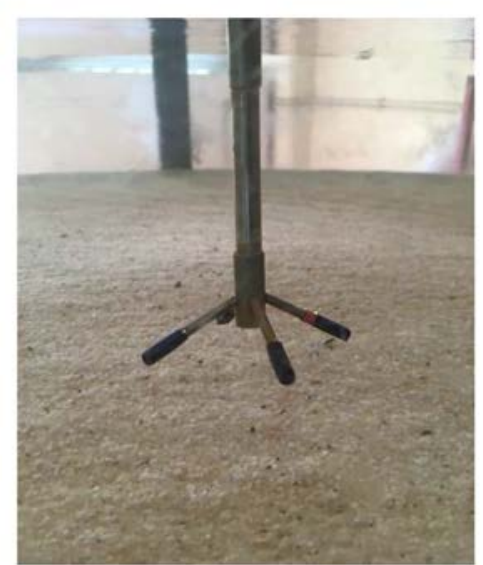

(b)

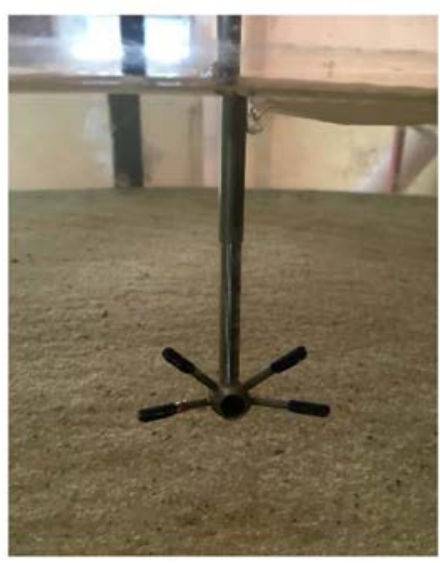

(c)

Figure 4. (a) The meshing diagram, (b) Vectrino 3D velocimeter down-looking probe, and (c) Vectrino 3D velocimeter side-looking probe.

rectangular pier, it does not divert the flow as much, thus creating less flow reversal.

Figure 5(c) and (d) illustrate the streamlines at water mid-depth. According to Figure 5(c), under the influence of the pier, the streamlines have been oriented towards the outer wall from an approximately 70-degree angle at the level of $50 \%$ of the water depth with installation of the rectangular pier. Further, the presence of sediments from approximately $100^{\circ}-130^{\circ}$ led to the orientation of streamlines towards the outer bank. According to Figure 5(d), with installation of the oblong pier, the streamlines are almost parallel to the channel walls in the second half of the bend due to the absence of sediments at this level. In addition, the streamlines further orient towards the outer wall of the bend in the first half with installation of the oblong pier, as it was the case with the rectangular pier.

Figures 5(e) and (f) indicate that the variations of streamlines near the bed level are mostly due to the flow interactions with sedimentary piles, and since there is a larger volume of sediments on the downstream side of the rectangular pier than those on the oblong pier, the streamline deviations at the level near the bed are also higher around the rectangular pier than those around the oblong pier. For instance, the sedimentary pile in the vicinity of the inner wall is extended from around the $70^{\circ}$ angle to the end of the bend, and it covers approximately $80 \%$ of the channel width near the end of the bend in the case of the rectangular pier. Figure 6 illustrates the streamlines at the channel cross-section in the upstream nose of the piers. The piers are also shown in this figure for clarity. In addition, the location of the collar is shown in red color. For the rectangular pier, Figure 6(a) shows the generation of down flow streams at the upper levels of the flow depth from a distance of $10 \%$ of the channel width from the inner bank as a result of the interaction of lateral flows with the pier body. A rather strong vortex flow at the outer half of the channel width at a distance of $55-75 \%$ of the channel width from the inner bank is also created that covers approximately half of the flow depth. On the contrary, Figure 6(b) shows that for the oblong pier with round edges of the nose, there is no vortex formation, and only downflow 


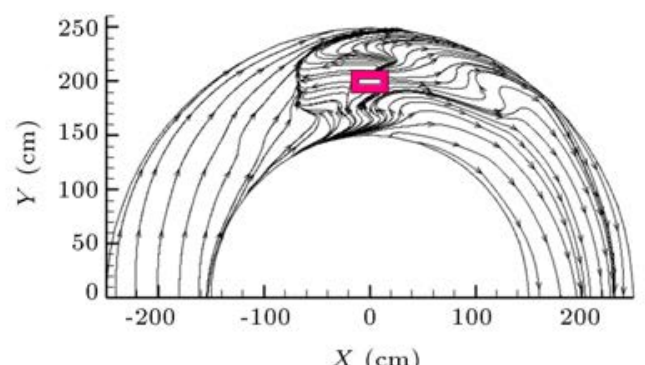

(a) $Z=0.95 y$, rectangular

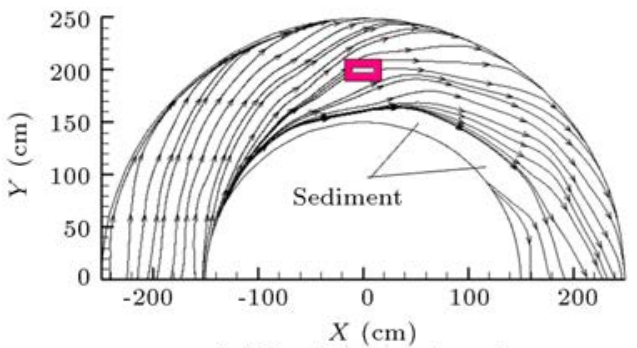

(c) $Z=0.5 y$, rectangular

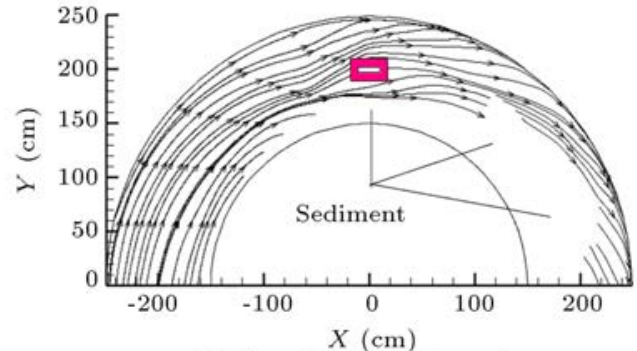

(e) $Z=0.05 y$, Rrctangular

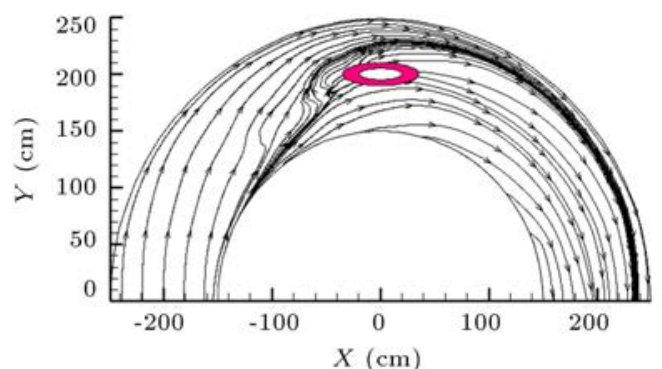

(b) $Z=0.95 y$, oblong

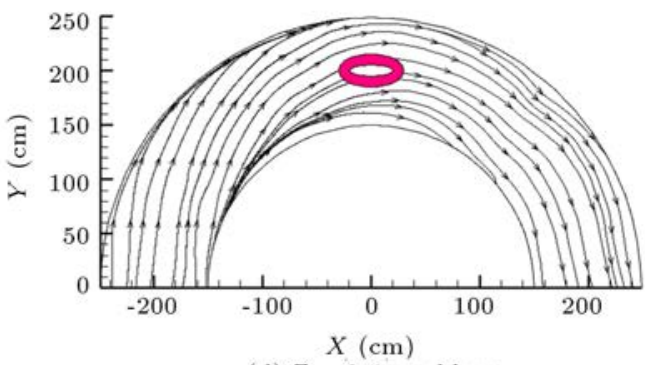

(d) $Z=0.5 y$, oblong

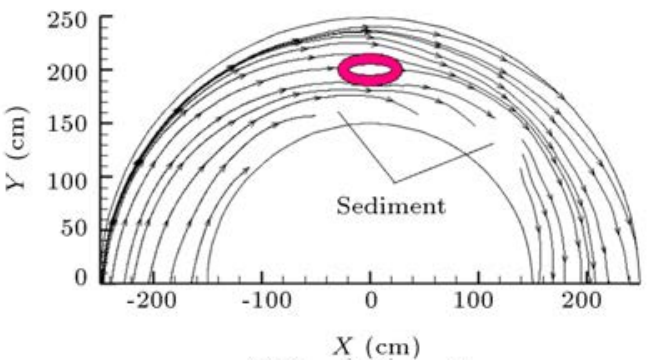

(f) $Z=0.05 y$, oblong

Figure 5. Sample streamlines on planes at levels of $95 \%, 50 \%$, and $5 \%$ of the flow depth from the initial bed level.

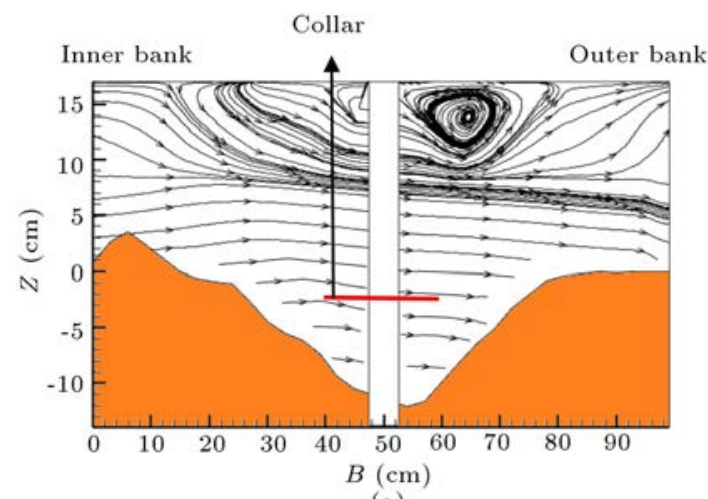

(a)

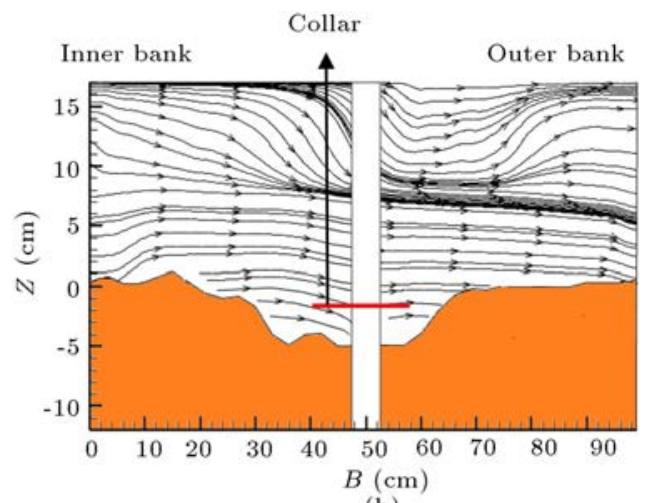

(b)

Figure 6. Sample streamlines at the channel cross-sections at the nose of the pier (at $88^{\circ}$ angle) around (a) the rectangular pier and (b) the oblong pier.

streams are created in the vicinity of the pier from a distance of around $40 \%$ of the channel width from the inner bank. Figure 6 also shows that the scour around the rectangular pier is much deeper than that around the oblong pier. Furthermore, for both cases, upstream flows are created near the outer bank.
Figure 7 illustrates the streamlines on a vertical longitudinal section along the centre of the bend channel. For both piers, this figure shows that the streamlines are diverted downwards from around the $50^{\circ}$ angle at the upper levels of the flow. Figure 7 (a) shows that the interaction of the flow with the 

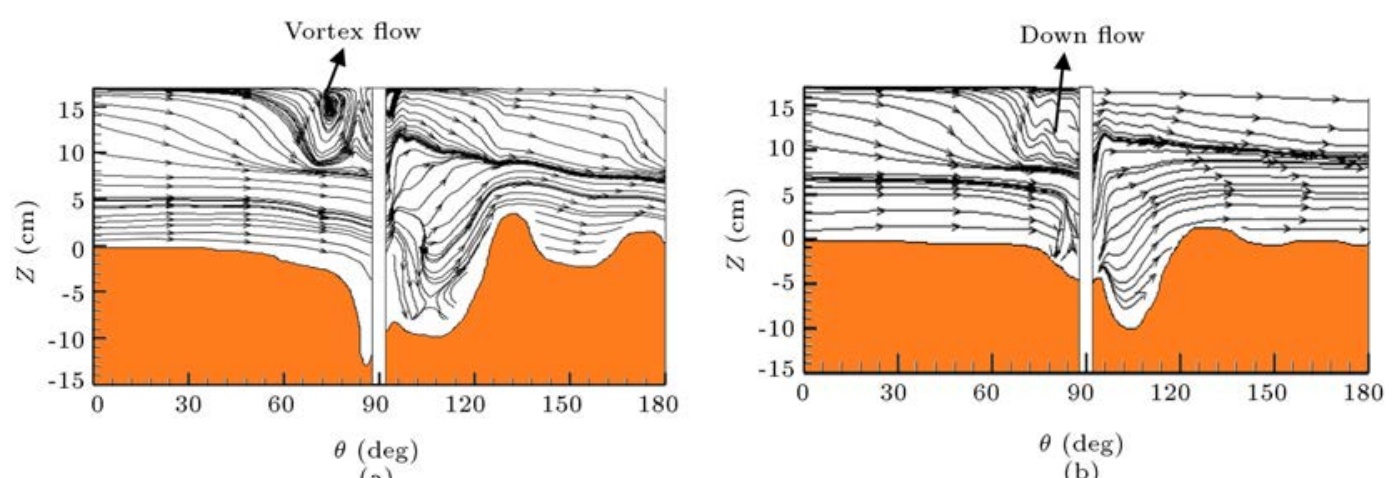

(a)

(b)

Figure 7. Samples streamlines in a vertical plane at the center of the curved channel with piers at $90^{\circ}$ : (a) Rectangular pier and (b) oblong pier

rectangular pier results in generation of a vortex flow in the vicinity of the upstream nose of the pier and near that, in turn, causes reverse flow near the water surface. Figure 7(b) shows down-sloped flow streams around the oblong pier in this area.

As observed in Figure 7(a) and (b), the maximum scour depth with installation of the rectangular pier occurs at the upstream nose of the pier; however, there are no large scour holes created on the upstream side of the oblong pier, probably due to the presence of the collar that has made an obstacle for vortex generation and, in turn, for creation of very deep scouring in this region. However, on the downstream side of the piers, where the effect of the collar fades, down flow streams lead to creation of massive scour holes at the distance between angles of $90^{\circ}$ and $110^{\circ}$. Sediments removed from this area are carried by the main flow stream and deposited downstream where the flow velocity is reduced. After about the $140^{\circ}$ angle, as a result of distancing from the location of the pier and collar, the variations of the streamlines for both piers are reduced.

Figure 8 presents the contours of tangential velocity $\mathrm{U}$, radial velocity $\mathrm{V}$, and vertical velocity $\mathrm{W}$ at the $5 \%$ level of flow depth from the initial bed level for both rectangular and oblong piers. According to Figure 8 (a) and (b), in the first half of the bend up to about the angle of $80^{\circ}$, the maximum tangential velocity for both piers is created near the inner wall. In the angular location between $80^{\circ}$ and $90^{\circ}$, the maximum tangential velocity occurs in the mid-channel under the influence of the pier and the resulting constriction. However, the interaction of the flow with the pier reduces the tangential velocity at the downstream of the pier, and this reduction continues to around the $110^{\circ}$ angle in the middle of the channel width. In addition, the maximum tangential velocity in the second half of the bend occurs near the outer wall. According to Figure 8(a), in the case of the rectangular pier, the presence of the large volume of deposited sediments at downstream of the pier reduces the tangential velocity in the vicinity of the outer bank at angles ranging from $130^{\circ}$ to $150^{\circ}$. In addition, as depicted in Figure 8(a), with installation of the rectangular pier, the maximum tangential velocity is $56.5 \mathrm{~cm} / \mathrm{s}$ at the angle of $92^{\circ}$ and a distance of $60 \%$ of the channel width from the inner bank, i.e., in the vicinity of the outer wall of the pier due to section constriction caused by pier installation. However, according to Figure 8(b) for the oblong pier, the maximum tangential velocity of $48.2 \mathrm{~cm} / \mathrm{s}$ occurs at the end of the bend (at $180^{\circ}$ angle) at a distance of $4 \%$ of the channel width from the outer bank due to the smaller volume of sediments on the downstream side of the pier.

According to Figure 8(c) and (d), the negative radial velocity towards the inner bank is higher than the positive radial velocity towards the outer bank in the experiments for both piers. This case is particularly observed in the first half of the bend mainly due to the presence of the secondary flows in the bend that are directed towards the inner bank near the bed, thus leading to accumulation of sediment in the vicinity of the inner wall. However, as a result of the interaction between the flow and the pier body in the location of the piers, this trend is disturbed and both positive and negative radial velocity values are observed in this area. In fact, due to the exerted constriction, the maximum positive and negative radial velocities occur around the piers. According to Figure 8(c), the maximum positive radial velocity around the rectangular pier is $25 \mathrm{~cm} / \mathrm{s}$ that occurs at the $88^{\circ}$ angle at a distance of $75 \%$ of the channel width from the inner bank. Similarly, the maximum negative radial velocity of $14.6 \mathrm{~cm} / \mathrm{s}$ around this pier occurs at the $90^{\circ}$ angle and a distance of $15 \%$ of the channel width from the inner bank. Positive radial velocity also occurs in the outer half of the channel due to the presence of sediments coverage of the inner bank.

For the installation of the oblong pier, the maximum positive radial velocity is $13.6 \mathrm{~cm} / \mathrm{s}$, which is created at the angle of $88^{\circ}$ near the inner bank, as seen in Figure 8(d). The maximum negative radial 


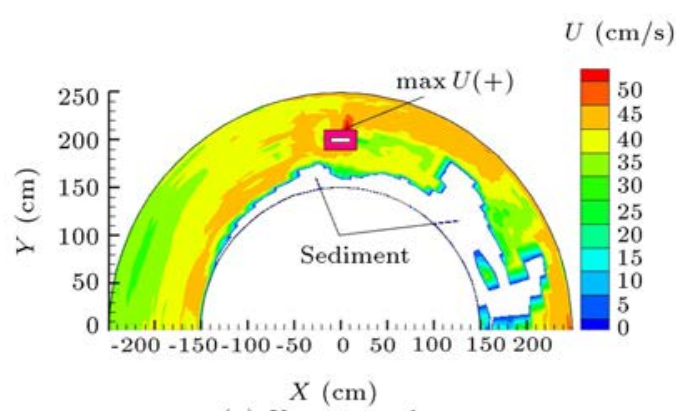

(a) $U$, rectangular

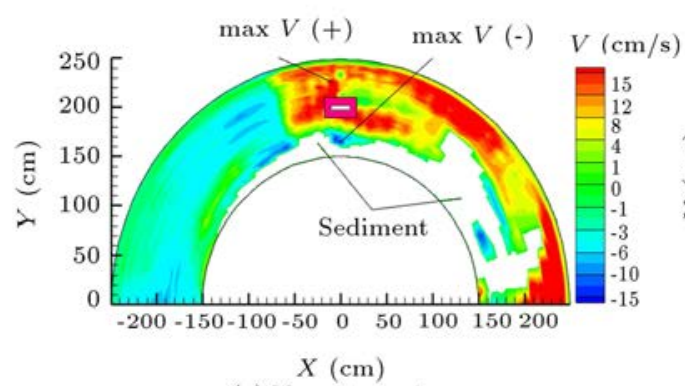

(c) $V$, rectangular

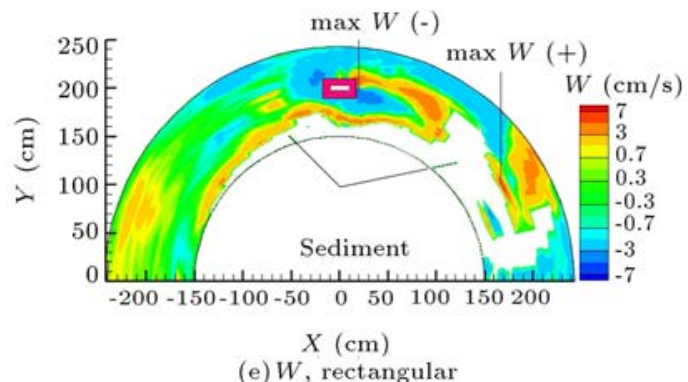

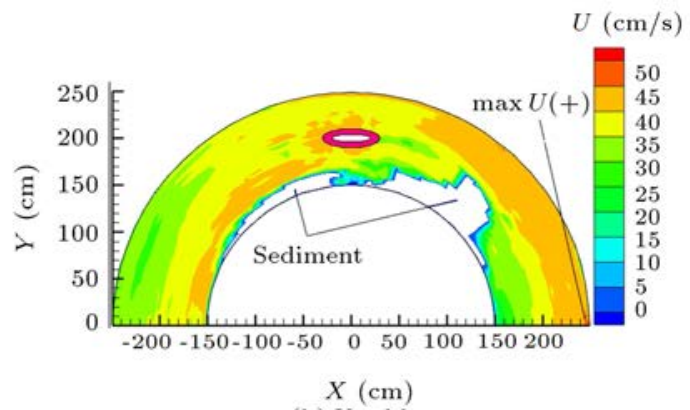

(b) $U$, oblong

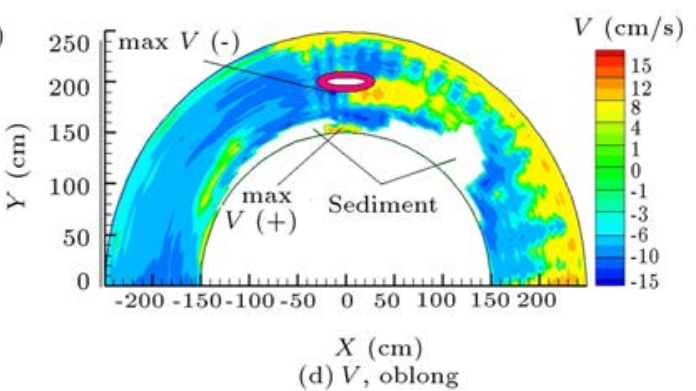

(d) $V$, oblong

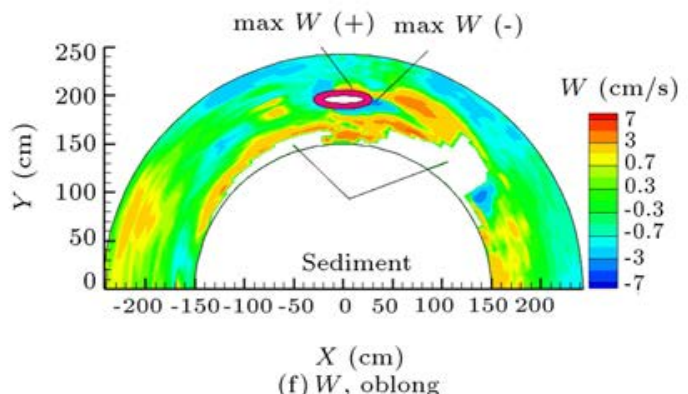

(f) $W$, oblong

Figure 8. Tangential $(U)$, radial $(V)$, and vertical $(W)$ velocity contours at the level of $5 \%$ of the flow depth from the initial bed level.

velocity is $24.1 \mathrm{~cm} / \mathrm{s}$, generated at an angle of $86^{\circ}$ and an approximate distance of $40 \%$ of the channel width from the inner bank.

In Figure 8(e) and (f), from the bend entrance to the vicinity of the pier in both cases, a positive vertical velocity in the vicinity of the inner bank and a downward (negative) vertical velocity in the centre of the channel are observed. This flow pattern contributes to sedimentation in the vicinity of the inner bank and scour at the mid-channel in the first half of the bend, as presented in Figure 3. With the collision of the flow with the pier, strong downward and upward flow streams form near the piers. The maximum downward velocity around both piers occurs at the angle of about $94^{\circ}$ in the middle of the channel. The maximum values of these downward flow velocities around the rectangular and oblong piers are 5.1 and $6.9 \mathrm{~cm} / \mathrm{s}$, respectively. These down flow streams are the main factors involved in the generation of the scour hole around the pier. Moreover, adjacent to negative ver- tical velocities, positive vertical velocities are observed towards the water surface, and a combination of these down flow and up flow streams leads to the generation of vortices around the pier.

Figure $8(\mathrm{f})$ indicates that the maximum positive vertical velocity around the oblong pier is $6.8 \mathrm{~cm} / \mathrm{s}$, which is created at the angle of $94^{\circ}$ in the middle of the channel. For the rectangular pier, however, the existence of the large volume of sediments downstream redirects the flow upward. As a result, the maximum upward velocity of $6.8 \mathrm{~cm} / \mathrm{s}$ occurs at the $150^{\circ}$ angle and a distance of $45 \%$ of the channel width from the inner bank, as depicted in Figure 8(e).

As the flow enters the bend, secondary flows are generated and the interaction between these secondary flows and the mainstream generates helical flows. To evaluate the strength of the secondary flows in the bend, Shukry (1950) suggested applying the ratio of the lateral flow kinetic energy to the mainstream kinetic energy [34], i.e.: 


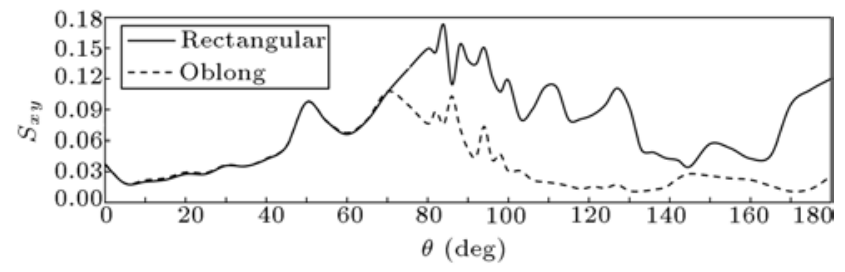

Figure 9. Variation of secondary flow intensity along the bend with rectangular and oblong piers.

$$
S_{x y}=\frac{K_{\text {Lateral }}}{K_{\text {Total }}}
$$

where $S_{x y}, K_{\text {Lateral }}$, and $K_{\text {Total }}$ are the secondary flow intensity, lateral flow kinetic energy, and mainstream kinetic energy, respectively.

Variations in the secondary flow power along the bend for both rectangular and oblong piers are presented in Figure 9. According to this figure, the intensity of the secondary flow in both experiments is the same up until the $70^{\circ}$ angle, which is quite low in the order of a few percent, reaching a maximum secondary flow intensity of about 0.1 at the $50^{\circ}$ angle. However, a series of fluctuations are observed in the close vicinity of the piers, especially in the range of $80^{\circ}-100^{\circ}$ angles. Of note, the intensity of the secondary flow increases near the upstream and downstream noses of both piers. With rectangular piers installed, the maximum intensity of the secondary flow of 0.17 near the upstream nose occurs at the $84^{\circ}$ angle, and the maximum intensity of the secondary flow of 0.15 near the downstream nose occurs at the $94^{\circ}$ angle. For the oblong pier, the maximum secondary flow power occurs at the $70^{\circ}$ angle at a value of 0.11 ; further, the maximum secondary flow intensity, equal to 0.1 , near the upstream nose occurs at the $86^{\circ}$ angle, and that near the downstream nose, equal to 0.07 , occurs at the $94^{\circ}$ angle. It is evident that in both cases, the secondary flow intensity in the vicinity of the upstream nose is higher than that in the vicinity of the downstream nose. Away from the pier to the end of the bend, the secondary flow intensity decreases. However, an increase is observed in the secondary flow intensity at the end of the bend. With the oblong pier, the maximum secondary flow power is reduced to approximately $35 \%$, in comparison with the case with the rectangular pier installed.

Another parameter, also a criterion of flow rotation, is angular velocity, which is a measure of fluid element rotation. The angular velocity is given as [35].

$$
\omega=\frac{1}{2}\left(\frac{\partial V}{\partial z}-\frac{\partial W}{\partial r}\right),
$$

where $V$ and $W$ represent mean radial and vertical velocity components, respectively.

The axial component of angular velocity for every element is calculated and averaged across the section,

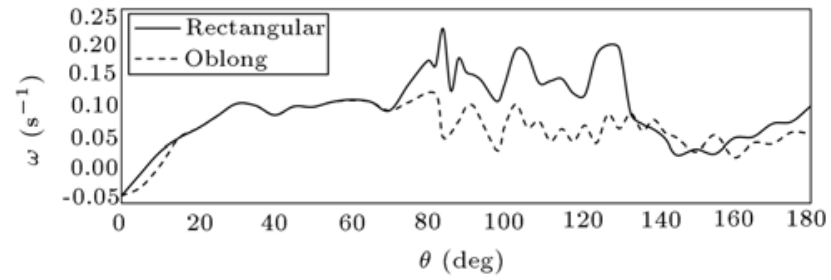

Figure 10. Mean angular velocity variation along the bend with installation of rectangular and oblong piers.

the results of which are shown in Figure 10 . As observed, for both rectangular and oblong piers, the mean angular velocity increases with a sharp slope from the bend entrance to approximately $30^{\circ}$ angle. Then, from the $30^{\circ}-70^{\circ}$ angles, it stays roughly constant with few small variations. Beyond the $70^{\circ}$ angle, the mean axial angular velocity increases significantly due to its proximity to the piers and interaction of the flow with their pier nose. In the presence of the rectangular pier, the maximum angular velocity of $0.22 \mathrm{~s}^{-1}$ occurs at the $84^{\circ}$ angle. Similar to a case with the oblong pier, the peak angular velocity of $0.12 \mathrm{~s}^{-1}$ occurs at the angle of $82^{\circ}$. Interestingly, for the oblong pier, the maximum angular velocity is approximately $45 \%$ less than that for the rectangular pier. Figure 10 also shows a high level of angular velocity fluctuations downstream of the pier up to about $130^{\circ}$ angle. For example, for the rectangular pier, at both $106^{\circ}$ (where the scour hole occurs) and $130^{\circ}$ (where the maximum sedimentation occurs) angles, sudden increases in the axial angular velocity are observed that reach $0.18 \mathrm{~s}^{-1}$ and $0.19 \mathrm{~s}^{-1}$, respectively. Furthermore, for the oblong pier, at both $92^{\circ}$ (adjacent to the downstream nose) and $103^{\circ}$ (where the maximum scour depth occurs) angles, an increase in the angular velocity is observed up to about $0.1 \mathrm{~s}^{-1}$. Beyond the $130^{\circ}$ angle downstream of the piers, fewer fluctuations of angular velocity are observed. Near the end of the bend, at an approximate angle of $160^{\circ}$, the axial angular velocity increases with a mild slope. Such an increase is more significant for the rectangular pier than that for the oblong pier.

The wall shear stress is the key parameter for bed load transport. Therefore, the shear stress near the bed that provides an estimate of the wall shear stress is one of the most important parameters contributing to the bed topography variations. Figure 11 illustrates the contours of the component of the Reynolds stresses $(\tau)$ at a level equal to $5 \%$ of the flow depth from the initial bed level around both piers. Such stresses are calculated using the following equations [36]:

$$
\begin{aligned}
& \tau_{U^{\prime} V^{\prime}}=-\rho \overline{U^{\prime} V^{\prime}}, \\
& \tau_{U^{\prime} W^{\prime}}=-\rho \overline{U^{\prime} W^{\prime}}, \\
& \tau_{V^{\prime} W^{\prime}}=-\rho \overline{V^{\prime} W^{\prime}},
\end{aligned}
$$




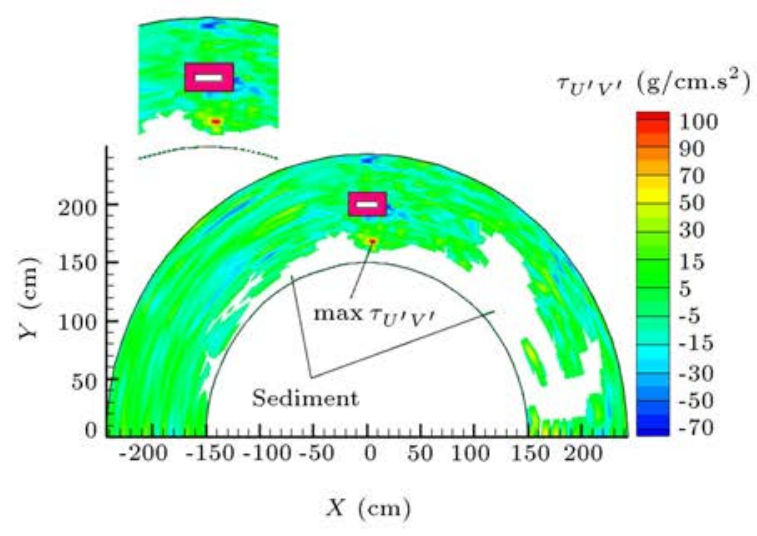

(a) Rectangular

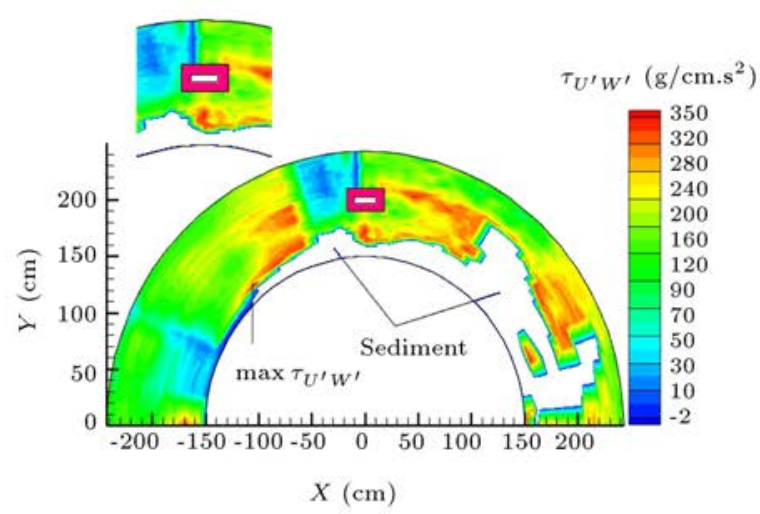

(c) Rectangular

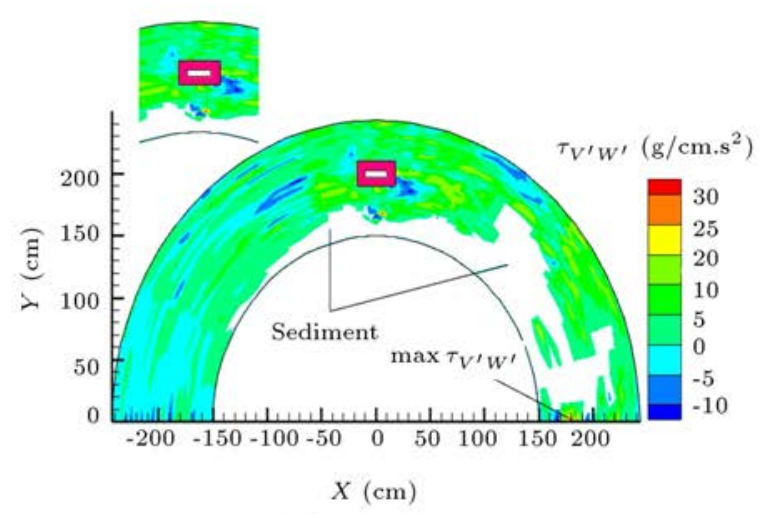

(e) Rectangular

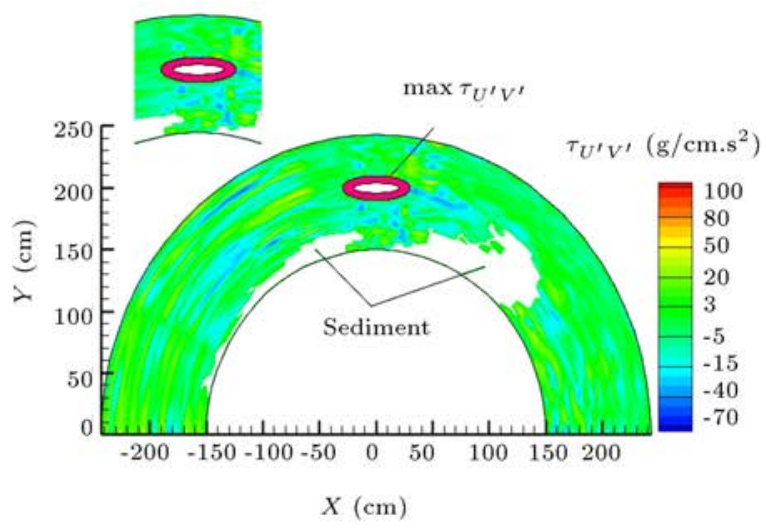

(b) Oblong

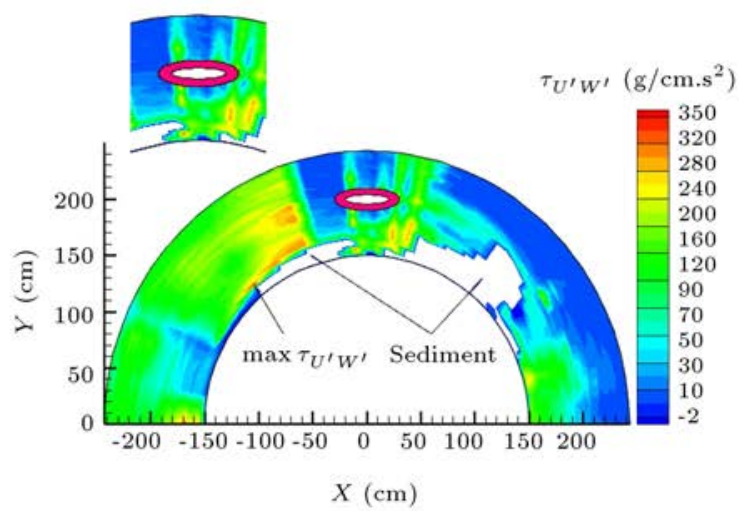

(d) Oblong

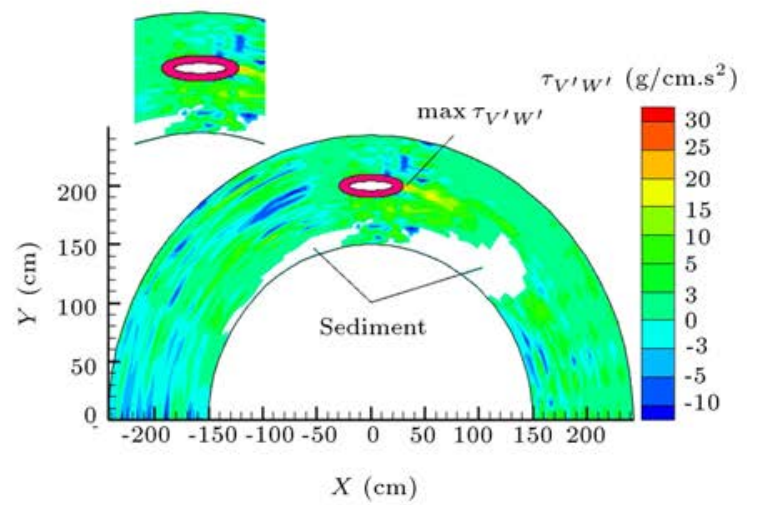

(f) Oblong

Figure 11. Contours of Reynolds stress components at a level of $5 \%$ of the flow depth from the initial bed level.

where $U^{\prime}, V^{\prime}$, and $W^{\prime}$ denote the tangential, radial, and vertical velocity fluctuations, respectively, at each point that are calculated through the following equations:

$$
\begin{aligned}
& U^{\prime}=U-\bar{U}, \\
& V^{\prime}=V-\bar{V}, \\
& W^{\prime}=W-\bar{W},
\end{aligned}
$$

where $U, V$, and $W$ represent tangential, radial, and vertical instantaneous velocities, respectively, at each point. In addition, $\bar{U}, \bar{V}$, and $\bar{W}$ are the mean values of tangential, radial, and vertical momentary velocities, respectively. Of note, the main contribution to the wall shear stress originates from $\tau_{U^{\prime} W^{\prime}}$ and $\tau_{V^{\prime} W^{\prime}}$.

Figure 11(a) and (b) show the contours of the Reynolds stress component $\tau_{U^{\prime} V^{\prime}}$. According to these figures, a region with low values of $\tau_{U^{\prime} V^{\prime}}$ was formed in both experiments at a distance of $30^{\circ}-70^{\circ}$ angles. However, due to the constriction caused by the pier installation, the value of $\tau_{U^{\prime} V^{\prime}}$ increases in the vicinity of the pier, and the maximum values of the shear stress 
$\tau_{U^{\prime} V^{\prime}}$ for both rectangular and oblong piers occur in the vicinity of the piers. For the rectangular pier, Figure 11(a) shows that the maximum value of $\tau_{U^{\prime} V^{\prime}}$ is about $144 \mathrm{~g} / \mathrm{cm} . \mathrm{s}^{2}$ which occurs at the $92^{\circ}$ angle at a distance of $18 \%$ of the channel width from the inner bank. For the oblong pier, the maximum $\tau_{U^{\prime} V^{\prime}}$ is 77.4 $\mathrm{g} / \mathrm{cm} . \mathrm{s}^{2}$ which occurs in the vicinity of the pier, as seen in Figure 11(b).

Figures $11(\mathrm{c})$ and $(\mathrm{d})$ show $\tau_{U^{\prime} W^{\prime}}$. According to these figures, the magnitude of $\tau_{U^{\prime} W^{\prime}}$ decreases at the beginning of the bend up to the $30^{\circ}$ angle, near the inner half of the channel width. However, thereafter, up to approximately $70^{\circ}$ angle, $\tau_{U^{\prime} W^{\prime}}$ increases which creates a region with high shear stress. These figures also show that the maximum $\tau_{U^{\prime} V^{\prime}}$ in the experiments involving both piers occurs near the $50^{\circ}$ angle at a distance of about $10 \%$ of the channel width from the inner bank, with a value of about $350 \mathrm{~g} / \mathrm{cm} . \mathrm{s}^{2}$. In addition, in proximity to the piers, especially in the second half of the channel width, the magnitude of $\tau_{U^{\prime} W^{\prime}}$ decreases as a result of the interactions of the flow with the pier; therefore, a low-stress zone is created towards the outer bank. Figure 11(c) shows that a region with high values of $\tau_{U^{\prime} V^{\prime}}$ is generated on the downstream side of the rectangular pier, mainly due to the existence of the large volume of sediments that significantly distorts the flow pattern. On the contrary, Figure 11(d) shows that on the downstream side of the oblong pier to the end of the bend, especially in the vicinity of the outer bank, the values of $\tau_{U^{\prime} W^{\prime}}$ decrease.

Figure 11(e) and (f) illustrate $\tau_{U^{\prime} W^{\prime}}$ contours in the bend in the presence of rectangular and oblong piers. As observed, a low-stress zone is created in the first half of the bend, especially in the range of $60^{\circ}$ to $70^{\circ}$. Figure $11(\mathrm{e})$ shows that in the second half of the bend with the rectangular pier, the values of $\tau_{V^{\prime} W^{\prime}}$ increase and the maximum $\tau_{V^{\prime} W^{\prime}}$ value of $37 \mathrm{~g} / \mathrm{cm} . \mathrm{s}^{2}$ occurs at the end of the bend (at an angle of $\left.180^{\circ}\right)$. This occurs as a result of the interaction between the flow and the large volume of sediments in the second half of the channel bend. However, according to Figure $11(\mathrm{f})$, the values of $\tau_{V^{\prime} W^{\prime}}$ for the oblong pier increase on the downstream side of the pier in the vicinity of the main scour hole, and the maximum $\tau_{V^{\prime} W^{\prime}}$ of $35.4 \mathrm{~g} / \mathrm{cm}^{-s^{2}}$ occurs at an angle of $96^{\circ}$ in the middle of the channel.

According to Figure 11, it can be concluded that the installation of an oblong pier instead of a rectangular pier reduces the maximum shear stress $\tau_{U^{\prime} V^{\prime}}$ by about $46 \%$. In this case, the maximum value of $\tau_{V^{\prime} W^{\prime}}$ decreases to about $4 \%$. While the maximum value of $\tau_{U^{\prime} W^{\prime}}$ was approximately the same in both experiments, this value around the rectangular pier in the major part of the bend, especially around the piers, is much higher than that around the oblong pier. In this respect, it can be concluded that installation of the oblong pier, instead of the rectangular pier, can decrease the magnitude of shear stress near the bed, mainly due to the long width of the rectangular pier nose and its sharp corners compared to the oblong pier, which results in higher resistance against the flow. The oblong pier with a round-edged nose is more aerodynamic which reduces the down flow streams and, consequently, decreases the shear stress around this pier. Higher values of the shear stress near the bed around the rectangular pier than those around the oblong pier result in stronger bed topography alterations and creation of larger and deeper scour holes, as can be observed in Figure 3 .

The TKE per unit mass is calculated using the following equation [36]:

$$
T K E=0.5\left({\overline{U^{\prime}}}^{2}+{\overline{V^{\prime}}}^{2}+{\overline{W^{\prime}}}^{2}\right) .
$$

Figure 12 depicts the TKE contours around both piers at a level of $5 \%$ of the flow depth from the initial bed level. According to Figure 12, in both experiments, at the distance of $60^{\circ}$ to $70^{\circ}$, a region with significant TKE is formed. However, by installing the oblong pier, the value of TKE decreased in comparison with the installation of the rectangular pier, especially in the second half of the bend. As shown in Figure 12(a), due to the increased flow velocity near the rectangular pier, a region with significant TKE is formed at about $90^{\circ}$ near the inner bank.
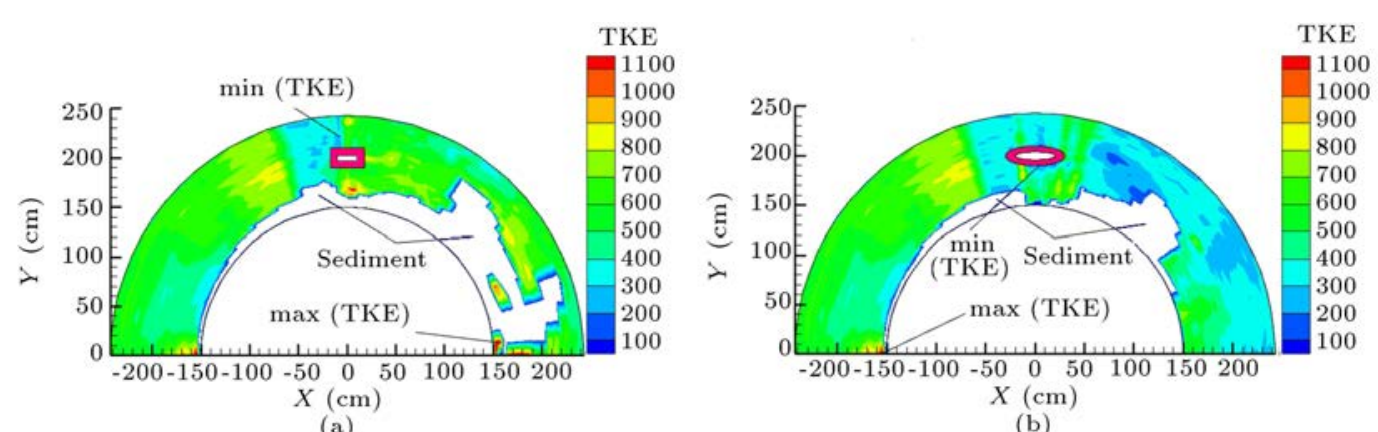

Figure 12. Contours of turbulence kinetic energy at a level of $5 \%$ of the flow depth from the initial bed level with installation of (a) the rectangular and (b) the oblong piers. 
With installation of the rectangular pier, the maximum kinetic energy occurs at the $175^{\circ}$ angle with a value of $1251 \mathrm{~cm}^{2} / \mathrm{s}^{2}$; in addition, with installation of the oblong pier, the peak kinetic energy occurs at the zero-degree angle with a value of $1215 \mathrm{~cm}^{2} / \mathrm{s}^{2}$ near the inner bank. In other words, the maximum kinetic energy with installation of the oblong pier is not significantly different from that with installation of the rectangular pier, and it is only reduced by $3 \%$.

\section{Conclusions}

In this study, the flow patterns around rectangular and oblong piers with collars located at the $90^{\circ}$ angle in the middle of the 180-degree sharp bend were studied experimentally using the Vectrino 3D velocimeter. Particular attention was given to the effect of the pier shape on the formation of resulting flow patterns of scours in the channel. Contour plots of mean velocity components, shear stress, kinetic energy, and flow streamlines were presented and discussed. In addition, the variations of mean angular velocity and secondary flow intensity were also evaluated. The main conclusions of the study are:

- The scour hole depth and the volume of the accumulated sediments were much higher with installation of the rectangular pier than those with the use of the oblong pier;

- The existence of the rectangular pier led to significant reverse flow near the free surface in the vicinity of the upstream nose of the pier. The reverse flow in the vicinity of the upstream nose of the oblong pier, however, is much lower than that in the case of the rectangular pier;

- The interaction of the flows with the piers body increased the vertical velocity component, and a number of down flow streams were generated around both piers, and a number of vortices were created around the rectangular pier;

- The maximum secondary flow intensity and angular velocity in both experiments occurred in the vicinity of the piers. The use of oblong pier decreased the maximum secondary flow intensity and angular velocity, respectively, by about $35 \%$ and $45 \%$ in comparison with installation of the rectangular pier;

- By installing the oblong pier, the values of shear stress decreased in comparison to those with installation of the rectangular pier;

- The existence of the rectangular pier created a region with significant turbulence kinetic energy near the inner bank at $90^{\circ}$.

\section{References}

1. Albayrak, I. and Lemmin, U. "Secondary currents and corresponding surface velocity patterns in a turbulent open-channel flow over a rough bed", Journal of Hydraulic Engineering, $\mathbf{1 3 7}(11)$, pp. 1318-1334 (2011). https://doi.org/10.1061/(ASCE)HY.19437900.0000438

2. Ataie-Ashtiani, B. and Aslani-Kordkandi, A. "Flow field around side-by-side piers with and without a scour hole", European Journal of Mechanics-B/Fluids, 36, pp. $152-166$ (2012). https://doi.org/10.1016/j.euromechflu.2012.03.007

3. Akib, S., Jahangirzadeh, A., and Basser, H. "Local scour around complex pier groups and combined piles at semi-integral bridge", Journal of Hydrology and Hydromechanics, 62(2), pp. 108-116 (2014). https://doi.org/ 10.2478/johh-2014-0015

4. Tao, J. and Yu, X. "Flow and scour patterns around bridge piers with different configurations: Insights from CFD simulations", In Geo-Congress 2014, Geocharacterization and Modeling for Sustainability, pp. 2655-2664 (2014).

5. Jaman, H., Das, S., Kuila, A., et al. "Hydrodynamic flow patterns around three inline eccentrically arranged circular piers", Arabian Journal for Science and Engineering, 42(9), pp. 3973-3990 (2017). https://doi.org/10.1007/s13369-017-2536-9

6. Keshavarzi, A., Shrestha, C.K., Zahedani, M.R., et al. "Experimental study of flow structure around two in-line bridge piers", In Proceedings of the Institution of Civil Engineers-Water Management, 171(6), pp. 311-327 Thomas Telford Ltd (2018). http://dx.doi.org/10.1680/jwama.16.00104

7. Jalil, S.A. "Analysis of the modeling outputs of shape factor effect on flow structure between bridge piers", Journal of University of Babylon, 26(4), pp. 208-221 (2018).

8. Chavan, R., Venkataramana, B., Acharya, P., et al. "Comparison of scour and flow characteristics around circular and oblong bridge piers in seepage affected alluvial channels", Journal of Marine Science and Application, 17(2), pp. 254-264 (2018). https://doi.org/10.1007/s11804-018-0016-6

9. Das, S. and Mazumdar, A. "Evaluation of hydrodynamic consequences for horseshoe vortex system developing around two eccentrically arranged identical piers of diverse shapes", KSCE Journal of Civil Engineering, 22(7), pp. 2300-2314 (2018). https://doi.org/10.1007/s12205-017-1842-9

10. Chen, S.C., Tfwala, S., Wu, T.Y., et al. "A hooked-collar for bridge piers protection: Flow fields and scour", Water, 10(9), p. 1251 (2018). https://doi.org/10.3390/w10091251

11. Chavan, R., Gualtieri, P., and Kumar, B. "Turbulent flow structures and scour hole characteristics around 
circular bridge piers over non-uniform sand bed channels with downward seepage", Water, 11(8), p. 1580 (2019). https://doi.org/10.3390/w11081580

12. Lee, S.O. and Hong, S.H. "Turbulence characteristics before and after scour upstream of a scaled-down bridge pier model", Water, 11(9), p. 1900 (2019). https://doi.org/10.3390/w11091900

13. Carnacina, I., Leonardi, N., and Pagliara, S. "Characteristics of flow structure around cylindrical bridge piers in pressure-flow conditions", Water, 11(11), p. 2240 (2019). https://doi.org/10.3390/w11112240

14. Vijayasree, B.A., Eldho, T.I., Mazumder, B.S., et al. "Influence of bridge pier shape on flow field and scour geometry", International Journal of River Basin Management, 17(1), pp. 109-129 (2019). https://doi.org/ 10.1080/15715124.2017.1394315

15. Choufu, L., Abbasi, S., Pourshahbaz, H., et al. "Investigation of flow, erosion, and sedimentation pattern around varied groynes under different hydraulic and geometric conditions: A numerical study", Water, 11(2), p. 235 (2019). https://doi.org/10.3390/w11020235

16. Gautam, P., Eldho, T.I., Mazumder, B.S., et al. "Experimental study of flow and turbulence characteristics around simple and complex piers using PIV", Experimental Thermal and Fluid Science, 100, pp. 193-206 (2019). https://doi.org/10.1016/j.expthermflusci.2018.09.010

17. Namaee, M.R. and Sui, J. "Velocity profiles and turbulence intensities around side-by-side bridge piers under ice-covered flow condition", Journal of Hydrology and Hydromechanics, 68(1), pp. 70-82 (2020). https://doi.org/10.2478/johh-2019-0029

18. Vijayasree, B.A., Eldho, T.I., and Mazumder, B.S. "Turbulence statistics of flow causing scour around circular and oblong piers", Journal of Hydraulic Research, 58(4), pp. 673-686 (2020).

https://doi.org/10.1080/00221686.2019.1661292

19. Lade, A.D., Deshpande, V., and Kumar, B. "Study of flow turbulence around a circular bridge pier in sand-mined stream channel", In Proceedings of the Institution of Civil Engineers-Water Management, pp. 1-21, Thomas Telford Ltd. (2020).

https://doi.org/10.1680/jwama.19.00041

20. Abhari, M.N., Ghodsian, M., Vaghefi, M., et al. "Experimental and numerical simulation of flow in a 90 bend", Flow Measurement and Instrumentation, 21(3), pp. 292-298 (2010). https://doi.org/10.1016/j. flowmeasinst.2010.03.002

21. Stoesser, T., Ruether, N., and Olsen, N.R.B. "Calculation of primary and secondary flow and boundary shear stresses in a meandering channel", $A d$ vances in Water Resources, 33(2), pp. 158-170 (2010). https://doi.org/10.1016/j.advwatres.2009.11.001

22. Uddin, M.N. and Rahman, M.M. "Flow and erosion at a bend in the braided Jamuna River", International Journal of Sediment Research, 27(4), pp. 498-509 (2012).
23. Gholami, A., Akbar Akhtari, A., Minatour, Y., et al. "Experimental and numerical study on velocity fields and water surface profile in a strongly-curved 90 open channel bend", Engineering Applications of Computational Fluid Mechanics, 8(3), pp. 447-461 (2014). https://doi.org/10.1080/19942060.2014.11015528

24. Vaghefi, M., Akbari, M., and Fiouz, A.R. "An experimental study of mean and turbulent flow in a 180 degree sharp open channel bend: Secondary flow and bed shear stress", KSCE Journal of Civil Engineering, 20(4), pp. 1582-1593 (2016). https://doi.org/10.1007/s12205-015-1560-0

25. Vaghefi, M., Ahmadi, A., and Faraji, B. "The effect of support structure on flow patterns around T-shape spur dike in 90 bend channel", Arabian Journal for Science and Engineering, 40(5), pp. 1299-1307 (2015). https://doi.org/ 10.1007/s13369-015-1604-2

26. Mehraein, M., Ghodsian, M., Mashizi, M.K., et al. "Experimental study on flow pattern and scour hole dimensions around a T-shaped spur dike in a channel bend under emerged and submerged conditions", International Journal of Civil Engineering, 15(7), pp. 1019-1034 (2017). https://doi.org/10.1007/s40999017-0175-x

27. Abdi Chooplou, C., Vaghefi, M., and Meraji, S.H. "Study of streamlines under the influence of displacement of submerged vanes in channel width, and at the upstream area of a cylindrical bridge pier in a 180 degree sharp bend", Journal of Hydraulic Structures, 4(1), pp. 55-74 (2018). https://doi.org/ 10.22055/JHS.2018.25552.1071

28. Asadollahi, M., Vaghefi, M., and Tabibnejad Motlagh, M.J. "Experimental and numerical comparison of flow and scour patterns around a single and triple bridge piers located at a sharp 180 degrees bend", Scientia Iranica, 28(1), pp. 1-14 (2021). https://doi.org/10.24200/SCI.2019.5637.1391

29. Moghanloo, M., Vaghefi, M., and Ghodsian, M. "Experimental investigation on the effect of increasing the collar thickness on the flow pattern around the oblong pier in $180^{\circ}$ sharp bend with balanced bed", Journal of Applied Fluid Mechanics, 13(1), pp. 245-260 (2019). https://doi.org/10.29252/jafm.13.01.30164

30. Asadollahi, M., Vaghefi, M., and Akbari, M. "Effect of the position of perpendicular pier groups in a sharp bend on flow and scour patterns: numerical simulation", Journal of the Brazilian Society of Mechanical Sciences and Engineering, 42(8), pp. 1-15 (2020). https://doi.org/10.1007/s40430-020-02503-2

31. Sedighi, F., Vaghefi, M., and Ahmadi, G. "The effect of inclined pair piers on bed topography: Clear water, incipient motion and live bed", Iranian Journal of Science and Technology, Transactions of Civil Engineering, 45(3), pp. 1871-1890 (2021). https://doi.org/10.1007/s40996-020-00481-y

32. Vaghefi, M. and Akbari, M. "A procedure for setting up a 180-degree sharp bend flume including construction and examinations with hydraulic structures", 
Scientia Iranica, Transactions A, Civil Engineering, 26(6), pp. 3165-3180 (2019).

https://doi.org/10.24200/sci.2018.5033.1054

33. Chiew, Y.M. and Melville, B.W. "Local scour around bridge piers", Journal of Hydraulic Research, 25(1), pp. 15-26 (1987).

http://dx.doi.org/10.1080/00221688709499285

34. Shukry, A. "Flow around bends in an open flume", Transactions of the American Society of Civil Engineers ASCE, 115, pp. 751-779 (1950).

35. White, F.M., Fluid mechanics, McGraw-Hill Series in Mechanical Engineering, 7th Edition (2011).

36. Das, S., Das, R., and Mazumdar, A. "Comparison of characteristics of horseshoe vortex at circular and square piers", Research Journal of Applied Sciences, Engineering and Technology, 5(17), pp. 4373-4387 (2013).

\section{Biographies}

Arsalan Keshavarz was born in Kazeroun, Iran in 1994. He earned MSc degrees in Hydraulic Structures from Persian Gulf University, Bushehr, Iran in 2019. His research interests include the areas of river engineering, hydraulic structures, sedimentation, and flow and scour pattern.
Mohammad Vaghefi was born in Shiraz, Iran in 1973. He earned BSc and MSc degrees in Civil Engineering from Shiraz University, Iran in 1997 and 1999, respectively, and a $\mathrm{PhD}$ degree from Tarbiat Modares University, Tehran, Iran in 2009. He is currently the Associate Professor of Civil Engineering at Persian Gulf University, Bushehr, Iran. His areas of interest include hydraulic engineering, fluid mechanics, open channel hydraulics, river engineering, water flow engineering, hydrodynamics, and hydraulic structures. He has presented 220 papers in national and international conferences and has published 140 journal papers.

Goodarz Ahmadi is currently a Professor of Mechanical Engineering at Clarkson University, New York, USA. Professor Ahmadi has authored more than 600 papers in journals, in addition to three books and more 1100 papers in national and international conference proceedings. He has also given more than 160 keynote lectures and invited seminars worldwide. He is on the editorial advisory board of thirteen technical journals and is a fellow of ASME, ISME, and ISCE. He was also a Senior Research Associate at National Energy Technology Laboratory (NETL). 